Article

\title{
The Effects of Wet Compression by the Electronic Expansion Valve Opening on the Performance of a Heat Pump System
}

\author{
Kyoungjin Seong ${ }^{1}$, Daehui Lee ${ }^{1,2}$ and Jinho Lee ${ }^{1, *}$ \\ 1 School of Mechanical Engineering, Yonsei University, 50 Yonsei-Ro, Seodaemun-Ku, Seoul 03722, Korea; \\ 9394sung@gmail.com (K.S.); e.daehui@gmail.com or edaehui@yonsei.ac.kr (D.L.) \\ 2 R\&D Center of Doowon heavy industrial Co., Ltd., 51 Gwaneumdang-Gil, Juksan-Myon, Anseong-Si, \\ Gyeonggi-Do 17520, Korea \\ * Correspondence: jinholee@yonsei.ac.kr; Tel.: +82-2-2123-2816
}

Academic Editor: Takahiko Miyazaki

Received: 9 January 2017; Accepted: 1 March 2017; Published: 3 March 2017

\begin{abstract}
In this study, by controlling the Electronic Expansion Valve opening, the influence of wet compression on a heat pump system was experimentally investigated in different heating conditions. The results demonstrate that the discharge temperature decreased and the mass flow rate increased, due to quality of the rising liquid droplets. It was also found that the heating capacity and power input of wet compression increased more than that of dry compression, with a superheat of $10^{\circ} \mathrm{C}$. The maximum COP (Coefficient of Performance) exists at a specific quality of ca. 0.94 to 0.90 , as the power input in the region of wet compression is proportionally larger than the increase in the heating capacity, according to the decreasing quality. When the Entering Water Temperature of the Outdoor Heat Exchanger was $10{ }^{\circ} \mathrm{C}, 5{ }^{\circ} \mathrm{C}$, and $0{ }^{\circ} \mathrm{C}$, the COP increased by a maximum of ca. $12.4 \%, 10.6 \%$, and $10.2 \%$, respectively, in comparison to the superheat of $10{ }^{\circ} \mathrm{C}$. In addition, the superheat at the discharge line is proposed as a proper controlling parameter to adjust the quality at the suction line, by varying the opening of the expansion valve during wet compression.
\end{abstract}

Keywords: heat pump; wet compression; dry compression; electronic expansion valve opening; two-phase mixture; quality

\section{Introduction}

Due to its high efficiency and performance, a heat pump is commonly used as an energy-saving residential heating and cooling unit, and is being consistently developed for the improvement of system components, the optimization of configuration, and the control of the systems.

Generally, a heat pump has a dry compression cycle, where the irreversibility exists by a superheated refrigerant entering the compressor inlet [1]. However, some heat pump systems, such as a fixed orifice expansion valve, can occasionally run vapor-liquid compression due to charge balancing factors. The vapor-liquid compression in a heat pump system is called wet compression, which brings it closer to the Ideal Carnot Cycle for a pure refrigerant and closer to the Lorenz Cycle for non-azeotropic refrigerants, because the irreversibilities caused by vapor superheating during compression are prevented. It was shown that the advantage of a wet compression cycle offers the highest possible efficiency for thermodynamic cycles operating between two temperatures with a heat sink and heat source [2,3]. While some earlier works [4,5] showed improvements in the isentropic and volumetric efficiency of the compressor, they did not recommend using wet compression due to the following possible dangers. Firstly, wet compression may cause an abrupt increase of pressure at the cylinder head, which may damage the valve or cylinder. Another risk is the acceleration of 
the wear, because the droplets of liquid wash the lubricating oil from the walls of the cylinder [6]. In fact, the destructive increase of cylinder pressure during wet compression can only occur when the vapor quality is under 0.4 at the compressor inlet, but this condition is rare [7]. In addition, the accelerated wear of a cylinder could be reduced by fully evaporating the droplets of liquid during compression [8]. Thus, the number of liquid droplets and a finite time required for heat transfer during compression, are considered to be important for preventing an abrupt increase in the pressure and a greater wear of the cylinder. Sami et al. [9] reported that a 5\% liquid injection at the compressor inlet enhances the performance of a heat pump. Cho et al. [10] reported that the liquid refrigerant injection, under a low speed, increases the leakage between scroll wraps, but is very effective under a high speed. In general, for improving the performance and extending the operating range of the heat pumps, the wet compression injected refrigerant at the compressor inlet has been frequently used with a complicated injection circuit, in order to decrease the discharge temperature of the compressor inlet in severe climatic conditions [11,12]. R32, which is a recent potential substitute for R410A, shows a higher discharge temperature of the compressor when compared to R410A, which is a main factor that can reduce the operating range of the heat pumps [13]. If the injection cycle is used for R32 in extending the operating range, it may experience difficulties during the operation, due to the low mass flow rate and the small molecular weight, which increase the internal leakage in the compressor, causing a reduction in the performance of the compressor. These problems could be solved by wet compression, which could decrease both the internal leakage and the discharge temperature during compression. Instead of adopting a complicated injection circuit for this purpose, the Electronic Expansion Valve (EEV) could be used to obtain the wet refrigerant state of the compressor suction, by controlling the EEV opening; this alternative motivated the present study. Due to its wider working range, higher control accuracy, and fast response, the EEV could be more popular in heat pump applications [13]. It could also be implemented in a much simpler configuration in the heat pump system, with an accurate control of the wet refrigerant state at the compressor inlet.

In this paper, based on the considerations discussed above, we experimentally investigated the influence of wet compression with a suction side cooled compressor through the EEV control on the performance of a $3.5 \mathrm{~kW}$ heat pump system, with a focus on the heating application at different outdoor temperatures. The effects of wet compression on the performance of the heat pump system were investigated and discussed, with respect to the refrigerant quality at the compressor inlet. In addition, the superheat at the discharge line was discussed as a controlling parameter for adjusting the quality at the suction line, by varying the opening of the expansion valve during wet compression.

\section{Experimental Setup and Test Procedure}

Figure 1 shows the schematic diagram of a heat pump system with a rated heating capacity of $3500 \mathrm{~W}$ and a power input of $1270 \mathrm{~W}$, in accordance with the ISO 13256-2 [14]. The working fluid adopted was R32 (Sanowart, Zibo, China), which is a potential substitute for R410A. The system consists of a hermetic rotary compressor (LG, Seoul, Korea), two plate heat exchangers (Danfoss, Nordborgvej, Denmark) working as the condenser and the evaporator, respectively, and an electronic expansion valve (Sanhua, Hangzhou, China) with a step motor. Detailed specifications of the major components of the tested heat pump system are provided in Table 1.

The condenser was cooled and the evaporator was heated by circulating water, which was kept at a given temperature by two thermostats. The entering water temperature of the indoor heat exchanger (EWT of ID HEX) (Danfoss, Nordborgvej, Denmark) was set at $40{ }^{\circ} \mathrm{C}$, according to ISO 13256-2(14), and the water flow rate through the condenser and ethanol flow rate through the evaporator were measured by a turbine flow meter (Autoflow, Seoul, Korea) at a fixed rate of $0.6 \mathrm{~m}^{3} \cdot \mathrm{h}^{-1}$. The test condition of the heat pump system is presented in Table 2. 


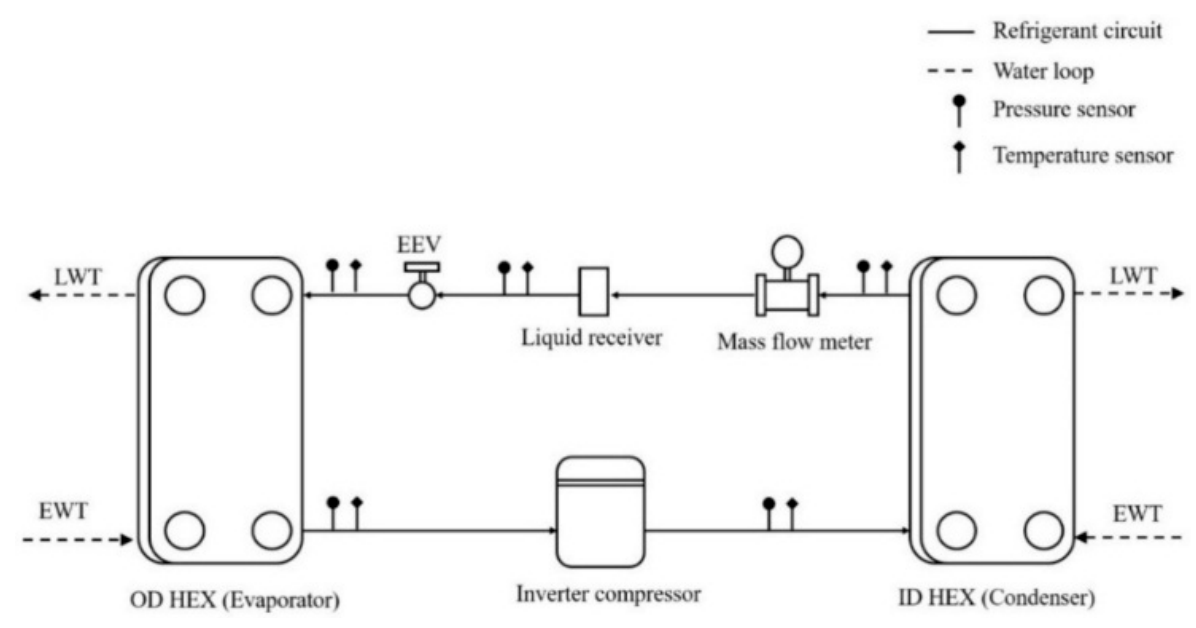

Figure 1. Schematic representation of the test rig.

Table 1. Specification of the major components.

\begin{tabular}{cc}
\hline Components & Specification \\
\hline Indoor heat exchanger & Manufacturer: Danfoss \\
Outdoor heat exchanger & Model No.: B3-030-20-3.0-HQ \\
\hline Compressor & Type: Brazed plate type heat exchanger \\
\hline Manufacturer: LG Model: GA102MFB \\
Type:Inverter Hermetic Rotary compressor \\
Displacement: 10.2 CC \\
Nominal cooling capacity: $3.5 \mathrm{~kW}$ \\
\hline Electric Expansion Valve & Manufacturer: Sanhua \\
& Model No. DPF(o) 1.4 \\
& Step (pulse): 2000 \\
& Orifice diameter: $1.4 \mathrm{~mm}$ \\
\hline
\end{tabular}

Table 2. Heating test conditions at a superheat of $10{ }^{\circ} \mathrm{C}$.

\begin{tabular}{|c|c|c|c|c|c|c|}
\hline \multirow[b]{2}{*}{ TEST } & \multicolumn{3}{|c|}{ Indoor heat exchanger } & \multicolumn{3}{|c|}{ Outdoor heat exchanger } \\
\hline & $\begin{array}{c}\text { EWT } \\
\text { (Entering Water Temperature) }\end{array}$ & $\begin{array}{c}\text { WFR } \\
\text { (Water Flow Rate) }\end{array}$ & $\begin{array}{l}\text { Discharge } \\
\text { Pressure }\end{array}$ & EWT & WFR & $\begin{array}{l}\text { Suction } \\
\text { Pressure }\end{array}$ \\
\hline ISO 13256-2 & $40^{\circ} \mathrm{C}$ & $0.6 \mathrm{~m}^{3} \cdot \mathrm{h}^{-1}$ & $\begin{array}{l}2946 \mathrm{kPa} \\
2846 \mathrm{kPa} \\
2800 \mathrm{kPa}\end{array}$ & $\begin{array}{l}10^{\circ} \mathrm{C} \\
5^{\circ} \mathrm{C} \\
0^{\circ} \mathrm{C}\end{array}$ & $0.6 \mathrm{~m}^{3} \cdot \mathrm{h}^{-1}$ & $\begin{array}{l}543 \mathrm{kPa} \\
440 \mathrm{kPa} \\
275 \mathrm{kPa}\end{array}$ \\
\hline
\end{tabular}

The experiment was first performed at a fixed superheat of $10{ }^{\circ} \mathrm{C}$, which was controlled by the EEV (Electric expansion valve) with the PID controller (Sanhua, Hangzhou, China). Then, in order to obtain the wet refrigerant state at the compressor inlet, the EEV opening was manually increased from the EEV opening position, corresponding to the given superheat. During the test, the temperature, pressure, mass flow rate, and power input of the heat pump system were recorded and monitored through the data acquisition system for $40 \mathrm{~min}$, with an interval of $2 \mathrm{~s}$. For the validation of the energy balance between the water and the refrigerant side, the water heat capacity was calculated by the water flow rate and the water temperature difference between the inlet and the outlet, and the refrigerant heat capacity was calculated by the enthalpy difference between the inlet and the outlet of the condenser. Both were in good agreement, within $\pm 5 \%$. The measurement accuracies and specifications of the sensors are summarized in Table 3 . The uncertainties of the heating capacity and Coefficient of Performance (COP) were estimated by single-sample analysis, according to ASHRAE (American Society of Heating, Refrigerating, and Air-conditioning Engineers) Guideline 2 [15], and were considered to be ca. $6.3 \%$. 
Table 3. Specification of the sensors.

\begin{tabular}{ccc}
\hline Parameter & Uncertainty & Full Scale \\
\hline Pressure transducer & $\pm 0.3 \%$ & $50 \mathrm{bar}$ \\
Temperature (T-type thermo-couples) at refrigerant side & $\pm 0.5^{\circ} \mathrm{C}$ & $-200-400{ }^{\circ} \mathrm{C}$ \\
Temperature (Pt-100 $\Omega$ ) at water side & $\pm 0.1{ }^{\circ} \mathrm{C}$ & $-100-100{ }^{\circ} \mathrm{C}$ \\
Mass flow meter & $\pm 0.25 \%$ & $10 \mathrm{~kg} \cdot \mathrm{min}^{-1}$ \\
Turbine flow meter & $\pm 0.5 \%$ & $2.2 \mathrm{~m}^{3} \cdot \mathrm{h}^{-1}$ \\
Power meter & $\pm 0.1 \%$ & $12 \mathrm{~kW}$ \\
\hline
\end{tabular}

\section{Results and Discussion}

\subsection{Estimation of Quality}

While estimating the state of the refrigerant at the compressor suction by the EEV opening control in a heat pump system, it is assumed that the capacity of the water and refrigerant side is equal, and that the refrigerant, through the expansion valve, is under a constant enthalpy process without experiencing a throttling loss, implying that the expansion process results in no heat loss. For the validation of the energy balance between the water and refrigerant side, the mass flow rate of the refrigerant was calculated by the water capacity and the enthalpy difference between the evaporator inlet and outlet. The error was confirmed between the calculated mass flow rate and the measured mass flow rate at the condenser outlet. As shown in Figure 2, the results were in good agreement, within $\pm 5 \%$ for the entire experimental range. The quality $(x)$ at the compressor suction was calculated using Equations (1)-(5), as follows:

$$
\begin{gathered}
\dot{Q}_{\mathrm{w}, \text { evap. }}=\dot{Q}_{\mathrm{r}, \text { evap. }} \\
\dot{Q}_{\mathrm{w}, \text { evap. }}=\dot{m}_{\mathrm{w}} \cdot c_{\mathrm{p}} \cdot\left(E W T_{\text {evap. }}-L W T_{\text {evap. }}\right) \\
\dot{Q}_{\mathrm{r} \text {,evap. }}=\dot{m}_{\mathrm{r}} \cdot\left(h_{\mathrm{o}, \text { evap. }}-h_{\text {in,evap. }}\right) \\
h_{\mathrm{o}, \text { evap. }}=\frac{\dot{Q}_{\mathrm{w}, \text { evap. }}}{\dot{m}_{\mathrm{r}}}+h_{\text {in,evap. }} \\
x=\frac{h_{\mathrm{o} \text { evap. }}-h_{\mathrm{l} \text {,sat. }}}{h_{\mathrm{g}, \text { sat. }}-h_{\mathrm{l}, \text { sat. }}}
\end{gathered}
$$

where $h_{\mathrm{o} \text {,evap. }}$ is the local specific enthalpy of the fluid (single phase or two-phase) at the compressor inlet, and $h_{1, \text { sat. }}$ and $h_{\mathrm{g} \text {,sat. }}$ are the saturated liquid and vapor enthalpies, respectively. Thus, $0<x<1$ $\left(h_{1, \text { sat. }}<h_{\mathrm{o}, \text { evap. }}<h_{\mathrm{g} \text {,sat. }}\right)$ is in the two-phase compression region (called wet compression), whereas $x>1\left(h_{\mathrm{o}, \text { evap. }}>h_{\mathrm{g}, \text { sat. }}\right)$ is in the superheated compression region (called dry compression).

Figure 3 shows the quality as a function of the EEV opening at a different entering water temperature of the outdoor heat exchanger (EWT of OD HEX). With an increase in the EEV opening, the quality decreased for all EWT of OD HEX, until it remained nearly constant at larger openings, depending on the EWT of OD HEX. The increase in the EEV opening results in an increase in the refrigerant flow rate, leading to a larger capacity of the refrigerant side than of the water side. Thus, because of the increase in the liquid droplets, the state of the compressor inlet varied to two-phase mixtures, with a quality lower than one. The slope of quality decreased gradually, owing to the decrease in the pressure difference between the high and low pressure side, by increasing the EEV opening. The quality remained constant after a specific EEV opening, namely the EEV openings of $35 \%$, $30 \%$, and $25 \%$ for the EWT of OD HEX at $10{ }^{\circ} \mathrm{C}, 5{ }^{\circ} \mathrm{C}$, and $0{ }^{\circ} \mathrm{C}$, respectively. Generally, if the system works at a constant superheat, it has to decrease the mass flow rate to meet the required superheat, as the evaporator capacity decreases with a decrease in the EWT of OD HEX. Thus, the quality decreased with a decrease in the EWT of OD HEX, for the same EEV opening (see Figure 3). 


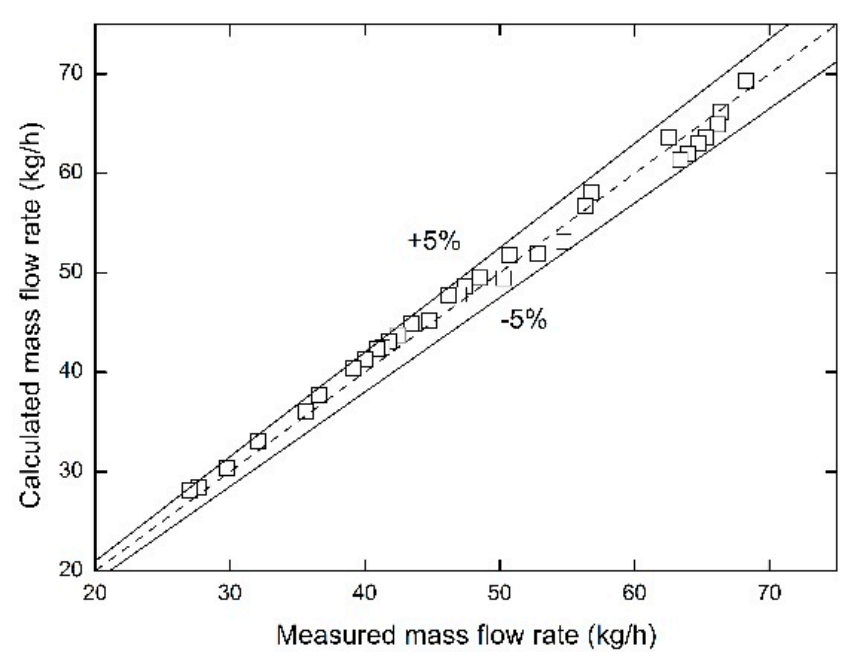

Figure 2. Measured vs. calculated mass flow rate.

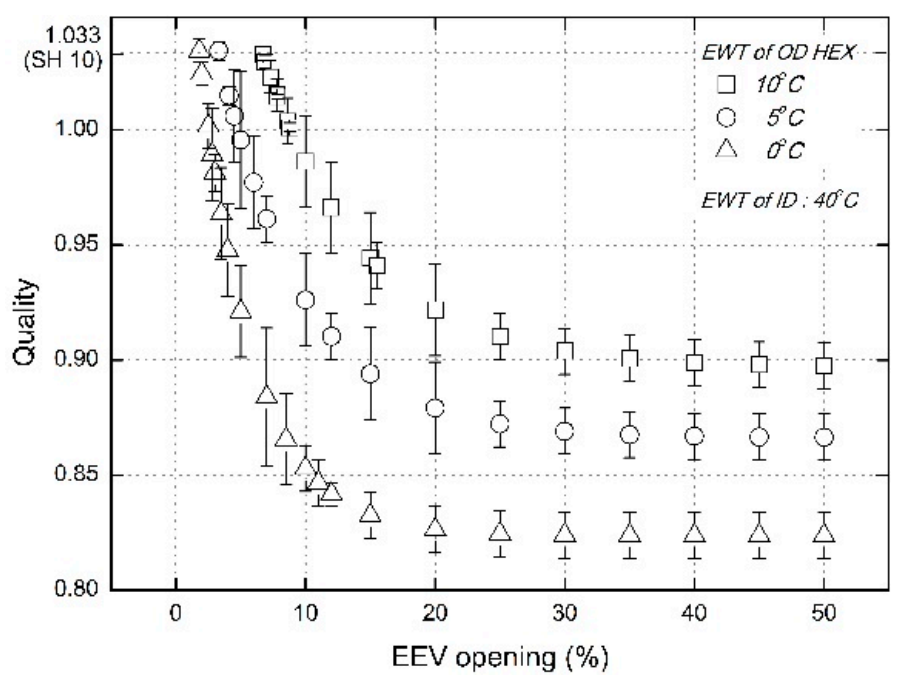

Figure 3. Quality as a function of the EEV (Electronic Expansion Valve) opening for different EWT of OD HEX (entering water temperature of the outdoor heat exchanger).

\subsection{System Performance According to Quality Variation}

Generally, compared to the conventional R410A, the internal gas leakage of a compressor increases, because the molecular weight of R32 is small. It leads to a reduction in the performance of the compressor. Furthermore, the reliability of a compressor can be decreased by a high discharge temperature. In order to analyze the effect of vapor-liquid compression on the compressor performance in different operating conditions, the volumetric and isentropic efficiencies were calculated as follows:

The volumetric efficiency $\left(\varepsilon_{\mathrm{v}}\right)$ is given by Equation (6).

$$
\varepsilon_{\mathrm{v}}=\frac{\dot{m} / \rho}{\dot{V}_{\mathrm{d}} v}
$$

where $\dot{m}$ is the mass flow rate, $\dot{V}_{\mathrm{d}}$ is the compressor displacement, $\rho$ is the density of the refrigerant, and $v$ is the compressor speed.

The isentropic efficiency $\left(\varepsilon_{\mathrm{s}}\right)$ is given by Equation (7). 


$$
\varepsilon_{\mathrm{s}}=\frac{h_{2, \text { Isen }}-h_{1}}{h_{2}-h_{1}} \approx \frac{\dot{m}\left(h_{2, \text { Isen }}-h_{1}\right)}{\dot{P}}
$$

where $h_{2, \text { Isen }}$ is the isentropic discharge enthalpy, $h_{1}$ is the suction enthalpy, $h_{2}$ is the discharge enthalpy, and $\dot{P}$ is the compressor power.

Figures 4 and 5 show the volumetric and isentropic efficiencies of the compressor as a function of quality for different EWT of OD HEX. As the quality decreased from SH $10{ }^{\circ} \mathrm{C}$ to the values of wet compression, the volumetric efficiency consistently increased up to ca. 0.9 , due to the increasing mass flow rate, and then decreased with a decreasing quality. When considering the isentropic efficiency, it increased up to the maximum value at a quality of about 0.95 , as the rise of the compressor power is smaller than that of the ideal power, owing to the rise of the mass flow rate. It then decreased with a decreasing quality.

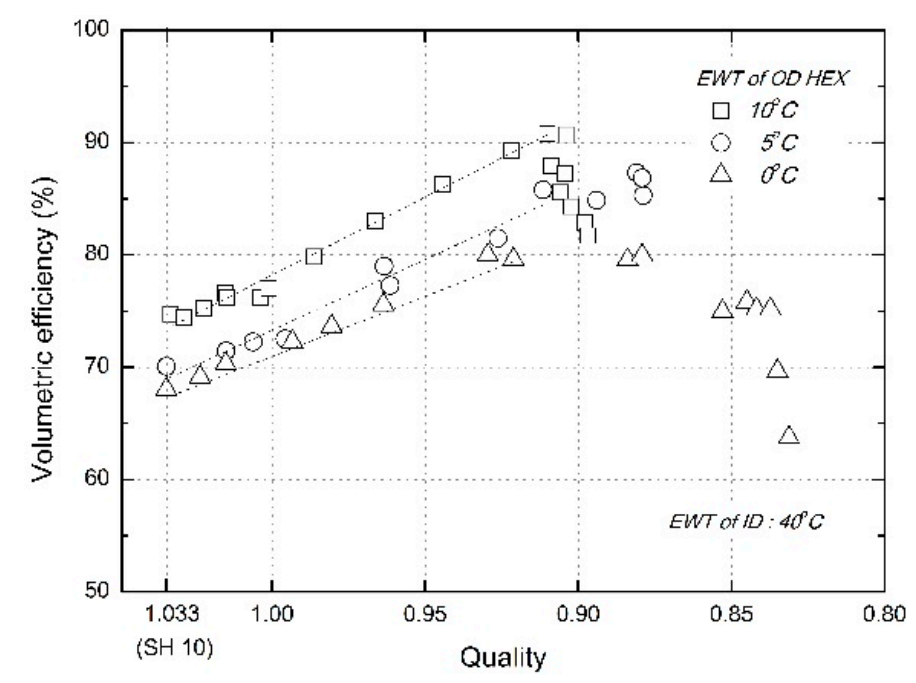

Figure 4. Volumetric efficiency as a function of quality for different EWT of OD HEX.

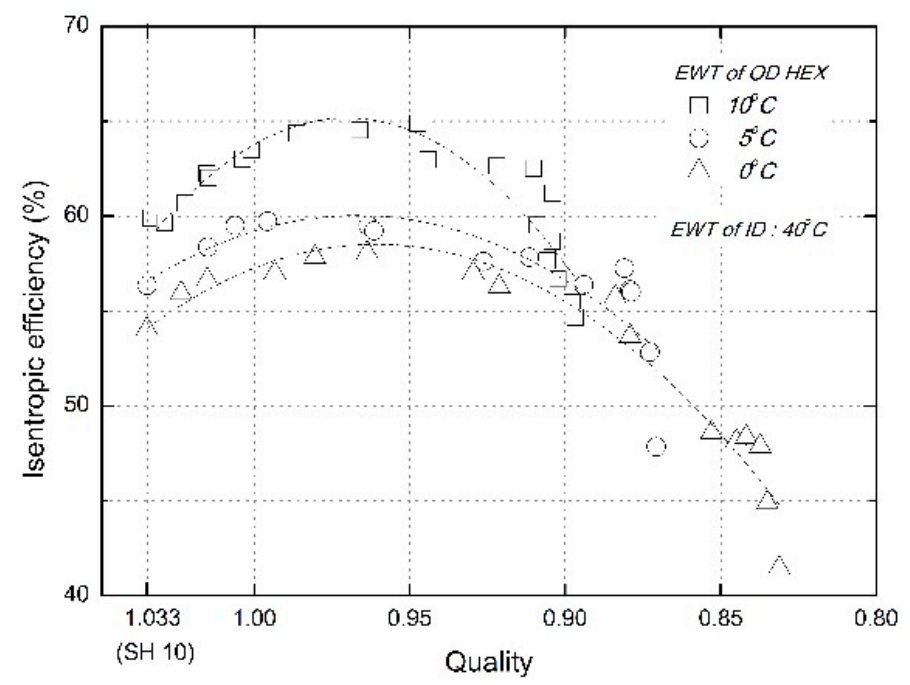

Figure 5. Isentropic efficiency as a function of quality for different EWT of OD HEX.

Figure 6 shows the variation in the pressure ratio against the quality from dry compression to wet compression. The pressure ratio decreases with a decreasing quality, as the evaporating pressure rise is higher than that of the condensing pressure. In addition, with an increase in the EWT of OD HEX, the rise in the evaporating pressure is generally higher than that of the condensing pressure; thus, the 
pressure ratio between them decreased, as the EWT of OD HEX increased. This can be calculated from the data in Figure 10a,b, which represent the variation in the suction and discharge pressure against the quality.

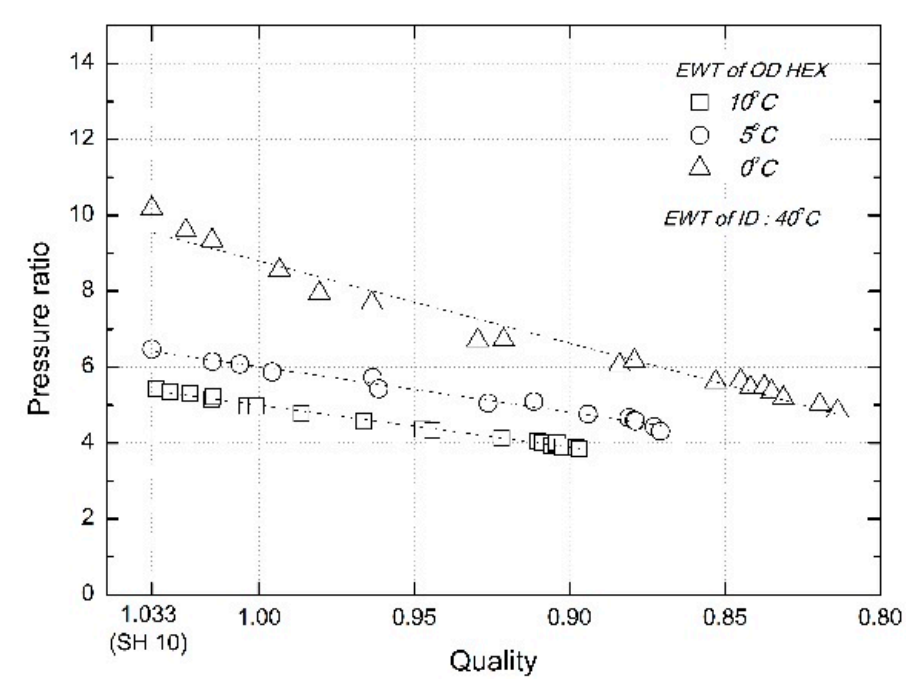

Figure 6. Pressure ratio as a function of quality for different EWT of OD HEX.

Figure 7 shows the suction temperature as a function of quality at different EWT of OD HEX. Since the saturation pressure is largely influenced by the EWT of OD HEX [16], the suction temperature dropped when the EWT of OD HEX decreased, due to the drop in the saturation pressure. The suction temperature decreased from $\mathrm{SH} 10{ }^{\circ} \mathrm{C}$ to a quality of one, and it presents a minimum value at a quality of one in this study. As the quality decreases in the area of wet compression, the suction temperature increases. This is due to the fact that the suction pressure is increased by the rising refrigerant inflow to the compressor inlet, with respect to a decreasing quality.

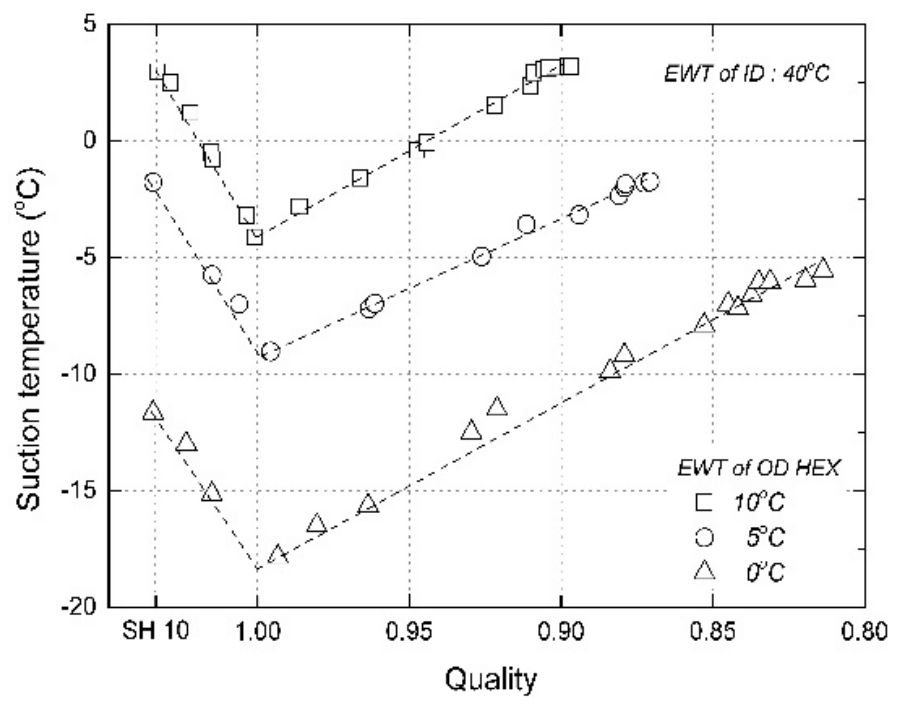

Figure 7. Suction temperature and superheat as a function of quality for different EWT of OD HEX.

Figure 8 shows the discharge temperature as a function of quality for different EWT of OD HEX. The discharge temperature is largely dependent on the pressure ratio and suction temperature of the system [17], which increases by a decrease in the pressure ratio and a rise in the suction temperature. However, during wet compression, despite an increase in the suction temperature (Figure 7), and a 
decrease in the pressure ratio (Figure 6), with a decrease in the quality of the two-phase mixtures, the discharge temperature consistently dropped, because the droplets of liquid were vaporized by the internal cooling heat transfer process during compression $[3,6]$.

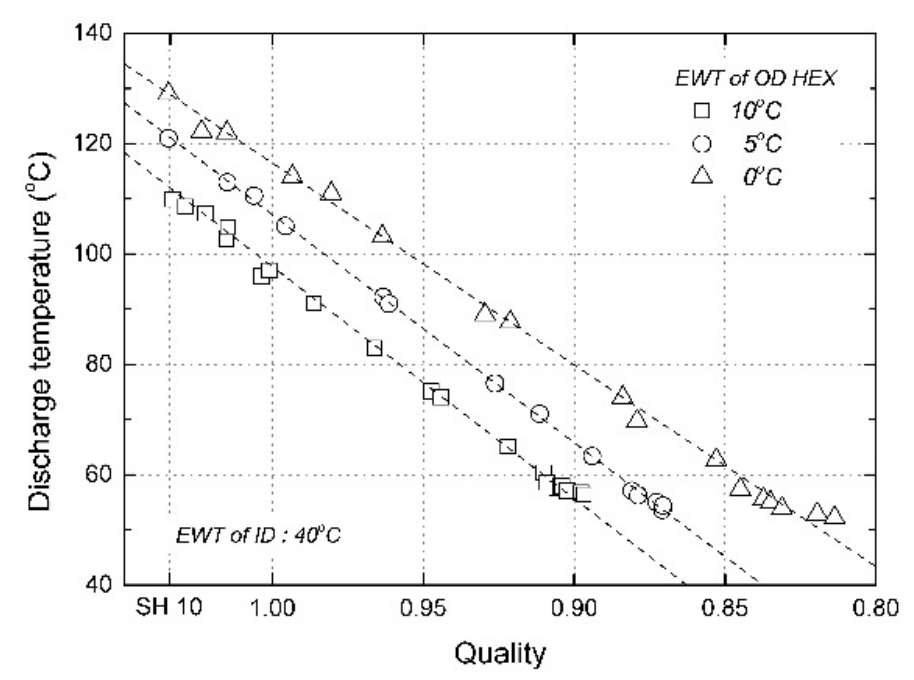

Figure 8. Discharge temperature as a function of quality for different EWT of OD HEX.

At a high pressure ratio in severe climatic conditions, such as in cold regions, the discharge temperature may exceed the allowed compressor discharge temperature, resulting in the chemical degeneration of the lubricating oil, causing excessive wear and reducing the lifetime of a compressor $[17,18]$. Thus, the reduction of quality at the compressor inlet can lead to a sufficient decrease in the discharge temperature, which is considerably attractive for a heat pump system operating at a high compression ratio.

Figure 9 shows the measured mass flow rate at the condenser outlet as a function of quality for different EWT of OD HEX. When the EWT of OD HEX is decreased, the mass flow rate decreased due to the decrease in the refrigerant density. The mass flow rate linearly increased with decreasing quality up to specific values for all EWT of OD HEX, with an increasing refrigerant inflow to the compressor. An increase of a maximum $70 \%, 80 \%$, and $88 \%$ in the mass flow rate was observed for EWT of OD HEX at $10^{\circ} \mathrm{C}, 5^{\circ} \mathrm{C}$, and $0{ }^{\circ} \mathrm{C}$, respectively. Under the quality of $0.91,0.88$, and 0.84 for EWT of OD HEX at $10{ }^{\circ} \mathrm{C}, 5^{\circ} \mathrm{C}$, and $0{ }^{\circ} \mathrm{C}$, respectively, the mass flow rate dramatically decreased, presumably due to the presence of overfull liquid droplets in the two-phase mixture. Similar results were reported by Afejei et al. [5] and Lee et al. [18]. These studies reported that the excessive liquid inflow in the compressor was not fully evaporated during compression. Thus, the rest of the liquid refrigerant accumulated in the compressor chamber. This could flow back into the suction chamber which, in turn, decreased the suction mass flow rate.

Figure 10 shows the suction (a) and discharge (b) pressure of the compressor as a function of quality for different EWT of OD HEX. When the EWT of OD HEX decreased, the suction pressure decreased by a drop in the evaporating temperature, leading to a decrease in the refrigerant density. This resulted in a decrease in the discharge pressure. Both the suction and discharge pressure increased on decreasing quality, by the rising refrigerant at the compressor inlet. In earlier studies $[19,20]$ focusing on an injection circuit, the discharge and suction pressure were unchanged, due to the cooling effect of the compressor head and fixed superheat; while, in the present study with no injection circuit, the discharge and suction pressure of the compressor increased. This leads to a decreasing pressure ratio as the increase in the suction pressure is larger than that of the discharge pressure. This is also related to an increase in the mass flow rate at the compressor suction, yielding a positive effect on the heating capacity of the heat pump system. This could lead to a decrease in the performance of the heat pump in the cooling condition, as the increase in the suction pressure leads to a decrease in 
the average temperature difference between the working fluid (refrigerant) and the secondary fluid (water) in the evaporator, although it increases the mass flow rate.

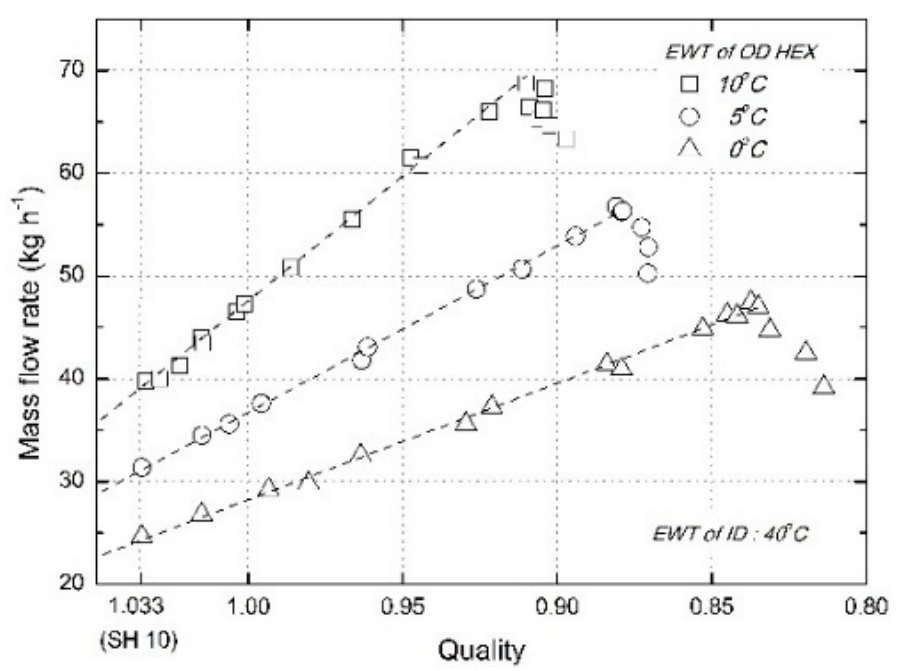

Figure 9. Measured mass flow rate at the condenser outlet as a function of quality for different EWT of OD HEX.

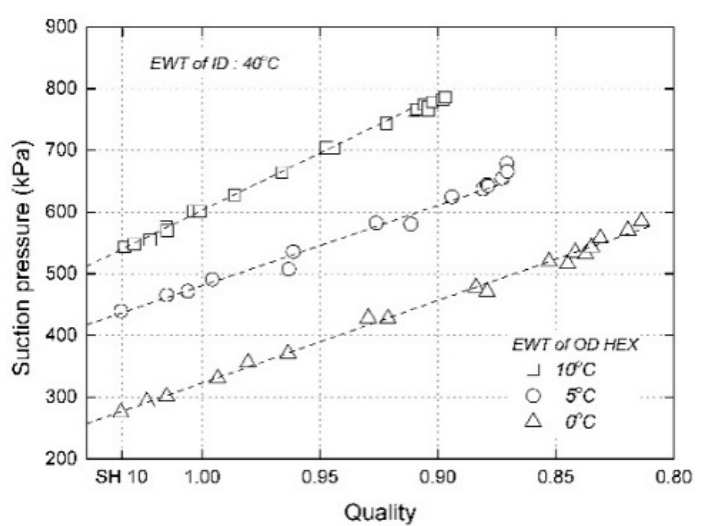

(a)

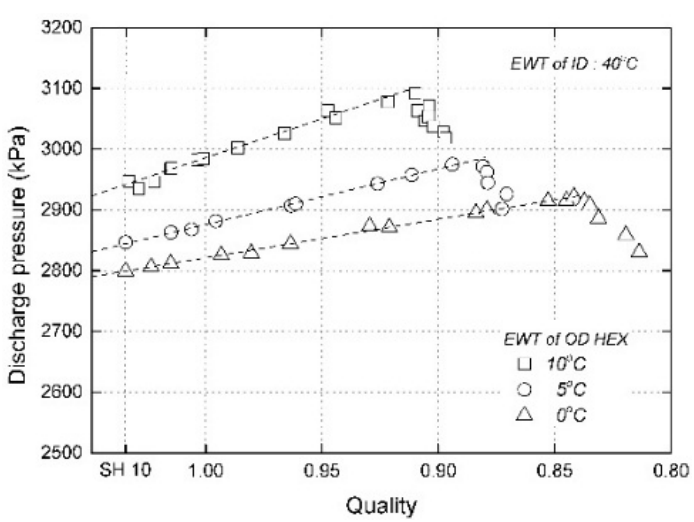

(b)

Figure 10. Suction and discharge pressure in the compressor as a function of quality for different EWT of OD HEX: (a) suction pressure; (b) discharge pressure.

Figure 11 shows the variation in the heating capacity as a function of quality for different EWT of OD HEX. When the EWT of OD HEX increased, the heating capacity increased as the refrigerant mass flow rate increased. It increased with respect to the decreasing quality, due to the increasing mass flow rate. Due to the loss of the mass flow rate caused by a back flow of liquid refrigerant into the suction chamber mentioned above, the heating capacity rapidly decreased under a quality of $0.91,0.88$, and 0.84 for EWT of OD HEX at $10{ }^{\circ} \mathrm{C}, 5^{\circ} \mathrm{C}$, and $0{ }^{\circ} \mathrm{C}$, respectively. Due to the larger increase in the mass flow rate, the slope of heat capacity, with respect to the quality, was steeper when the EWT of OD HEX increased. When the EWT of OD HEX was $10^{\circ} \mathrm{C}, 5^{\circ} \mathrm{C}$, and $0{ }^{\circ} \mathrm{C}$, compared to that of $\mathrm{SH} 10^{\circ} \mathrm{C}$, the heating capacity increased by a maximum of ca. $21 \%, 23 \%$, and $22 \%$, respectively. 


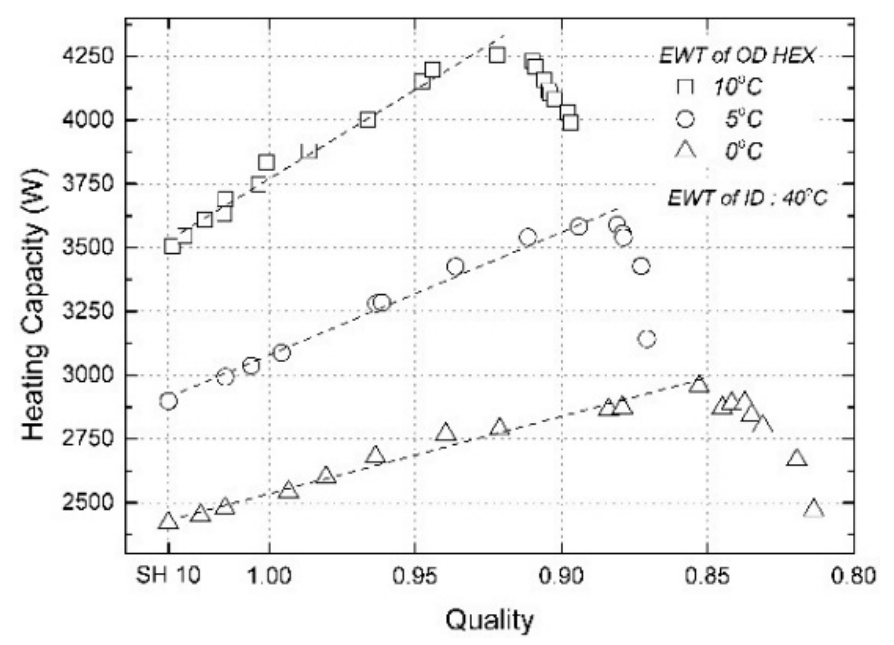

Figure 11. Heating capacity as a function of quality for different EWT of OD HEX.

Figure 12 shows the power input as a function of the quality for different EWT of OD HEX. As can be seen from the figure, the power input remained almost unchanged during dry compression in the range between $\mathrm{SH} 10^{\circ} \mathrm{C}$ and a quality of one. On the other hand, due to the increasing liquid droplets at the compressor suction, the power input linearly increased with a decreasing quality during wet compression. Generally, the compressor power decreases with respect to the reduction in the discharge temperature of the compressor (Figure 8), as the process approaches the isentropic compression process. However, due to the increasing refrigerant inflow to the compressor, the compressor power increased, in spite of a decrease in the discharge temperature with quality during wet compression. In previous research, it was observed that the increasing number of liquid droplets results in a rise in the compressor load [21]. In Figure 12, the power input rapidly decreased after the maximum value. This could be explained by the decrease in the mass flow rate by a back flow of liquid refrigerant into the suction chamber $[5,18]$. In our study, when the EWT of OD HEX was $10^{\circ} \mathrm{C}, 5^{\circ} \mathrm{C}$, and $0{ }^{\circ} \mathrm{C}$, the power input increased by maximum of $10 \%, 12.7 \%$, and $14.4 \%$, respectively, when compared to that of $\mathrm{SH} 10^{\circ} \mathrm{C}$.

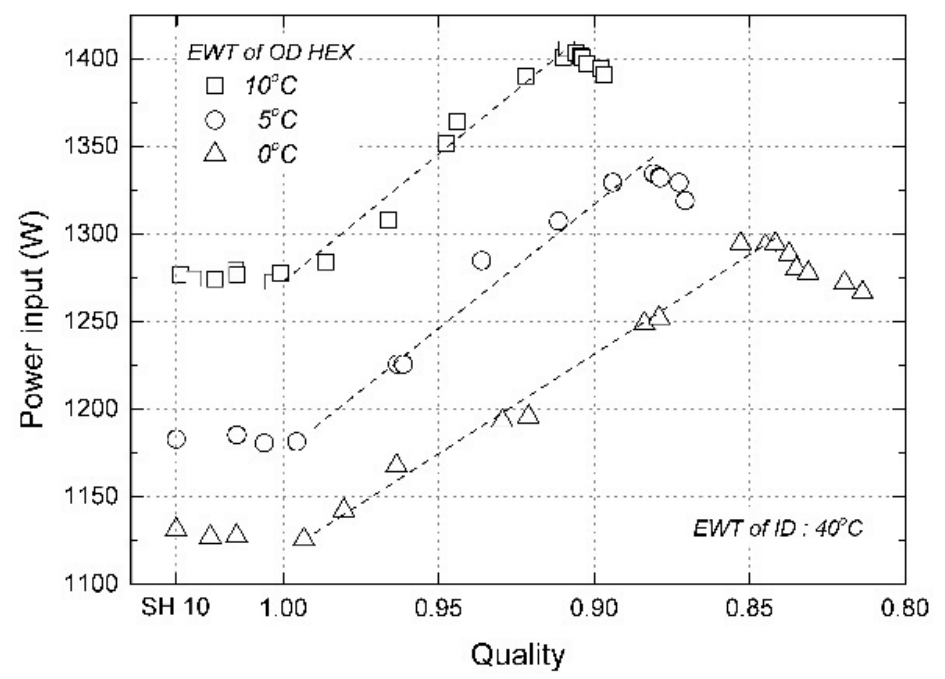

Figure 12. Power input as a function of the quality for different EWT of OD HEX. 
Figure 13 shows the COP (Coefficient of Performance) as a function of quality for different EWT of OD HEX. With an increasing EWT of OD HEX, the COP increased, resulting from the increase in the mass flow rate. From SH10, the COP also increased, until it reached the maximum value at a quality of ca. 0.94 to 0.90 in the two-phase mixture region, according to the EWT of OD HEX, and then decreased with the quality. This trend can be explained as follows. As the COP depends on the rate of the heating capacity to power input, the heating capacity consistently increases more than the power input with a decreasing quality, until the abrupt decrease, since the power input in the wet compression region is proportionally larger than the increase in the heating capacity, in accordance with the decreasing quality. Thus, a maximum COP occurs at specific qualities, i.e., as mentioned above, ca. 0.94 to 0.90 . When the EWT of OD HEX was $10^{\circ} \mathrm{C}, 5^{\circ} \mathrm{C}$, and $0{ }^{\circ} \mathrm{C}$, the COP increased by a maximum of ca. $12.4 \%$, $10.6 \%$, and $10.2 \%$, respectively, when compared to that of $\mathrm{SH} 10^{\circ} \mathrm{C}$.

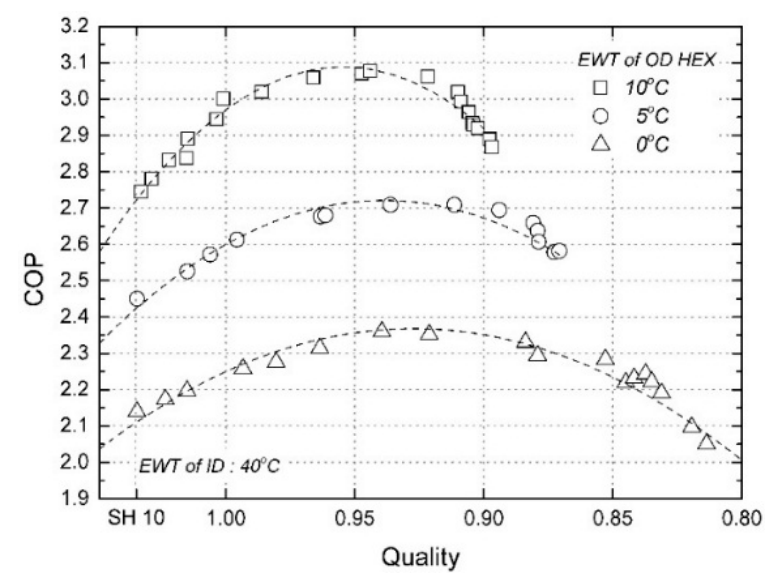

Figure 13. COP (Coefficient of Performance) as a function of quality for different EWT of OD HEX.

Figure 14 shows the process line of the vapor-liquid mixture at a quality of 0.94 at a EWT of OD HEX of $10{ }^{\circ} \mathrm{C}$, and compares it to that of $\mathrm{SH} 10^{\circ} \mathrm{C}$ in a pressure-enthalpy diagram. The discharge temperature for a quality of 0.94 and $\mathrm{SH} 10^{\circ} \mathrm{C}$ is $75^{\circ} \mathrm{C}$ and $110{ }^{\circ} \mathrm{C}$, respectively, with a difference of ca. $35^{\circ} \mathrm{C}$. As shown in Figure 14, wet compression is located closer to the isentropic line in the diagram, indicating a higher $\mathrm{COP}$ than $\mathrm{SH} 10^{\circ} \mathrm{C}$. Compared to the value of $\mathrm{SH} 10^{\circ} \mathrm{C}$, the rate of the increase in the evaporating pressure is higher than that of condensing pressure, as wet compression with the condensing pressure for the latter is larger than that of $\mathrm{SH} 10^{\circ} \mathrm{C}$. This results in a decrease in the pressure ratio, leading to an increase in the mass flow rate for wet compression. The isentropic efficiency increased by ca. $5 \%$, when compared to that of $\mathrm{SH} 10^{\circ} \mathrm{C}$.

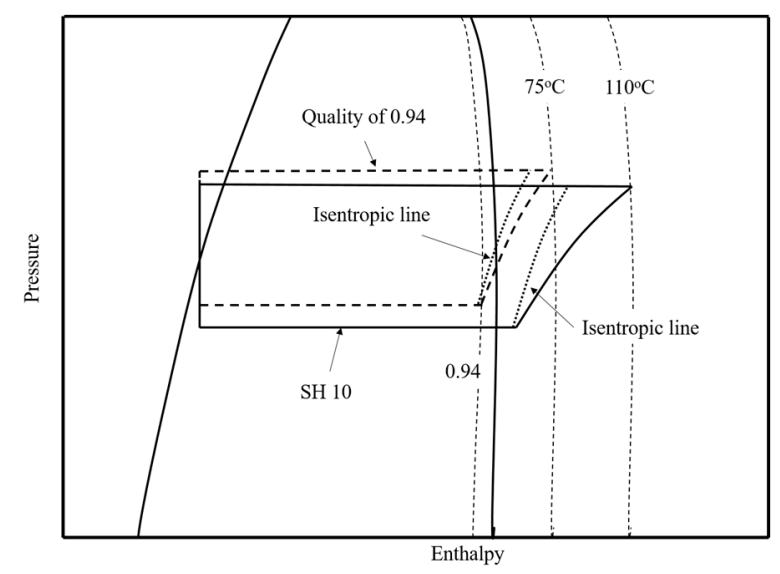

Figure 14. Effects of vapor-liquid compression from the experiment for different EWT of OD HEX. 
To sum up, an improvement in the performance of the vapor-liquid mixture compression on the heating capacity and COP was attainable and a drop in the discharge temperature was very effective. However, despite the reduction in the discharge temperature, the reliability of the compressor cannot be warranted, as the droplets of liquid during compression may wash the lubricating oil from the walls of the cylinder. However, the vapor-liquid mixture compression could be useful for performance improvement and a reduction in the discharge temperature, if the liquid droplets are fully vaporized by an internal heat transfer process that requires a finite amount of time [22]. Among the three most widely used positive displacement compressors (reciprocating, rolling-piston rotary, and scroll), the scroll compressor could also be appropriate for the wet compression technique, since the scroll compressor is less likely to have liquid slugging problems [4]. Thus, more extensive research, such as a durability test, is needed in this regard in the future.

\subsection{Superheat at Discharge as a Controlling Parameter}

In general, EEV varies to meet a specified superheat with a varying pressure and temperature at the compressor suction; however, when a two-phase flow (vapor phase and liquid phase) exists in the suction line of the compressor, the superheat is near zero (see Figure 15). It is thus difficult to achieve the required quality, as a controlling parameter of the expansion valve causes the hunting of TXV (Thermostatic Expansion Valve) [23].

Figure 16 shows the superheat at the discharge line as a function of the quality of different EWT of OD HEX. The superheat at the discharge line is calculated by subtracting the saturation temperature corresponding to the pressure measured at the discharge line, from the temperature measured at the same place. The optimum quality is determined with the maximum COP, and it was ca. 0.94 to 0.90 , when the EWT of OD HEX was $10{ }^{\circ} \mathrm{C}, 5^{\circ} \mathrm{C}$, and $0{ }^{\circ} \mathrm{C}$, respectively. As shown in Figure 16, the superheat at the discharge line was nearly constant, at ca. $22^{\circ} \mathrm{C}$. Therefore, from this result, the superheat at the discharge line could be proposed as a proper controlling parameter to adjust the quality at the suction line, by varying the opening of the expansion valve during wet compression; although, this requires a more extensive study to confirm the findings.

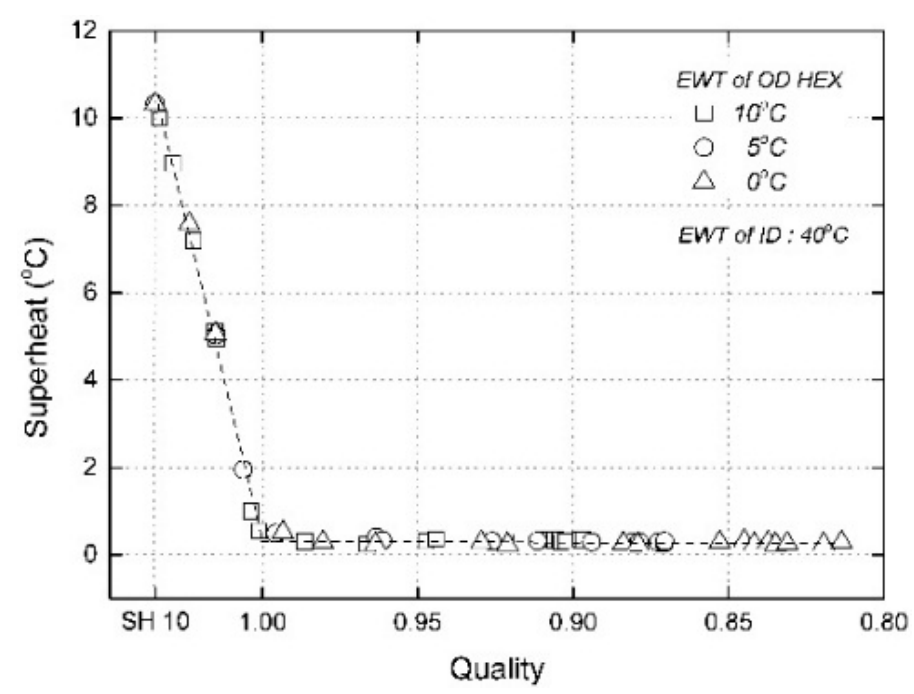

Figure 15. Superheat at the suction line as a function of quality for different EWT of OD HEX. 


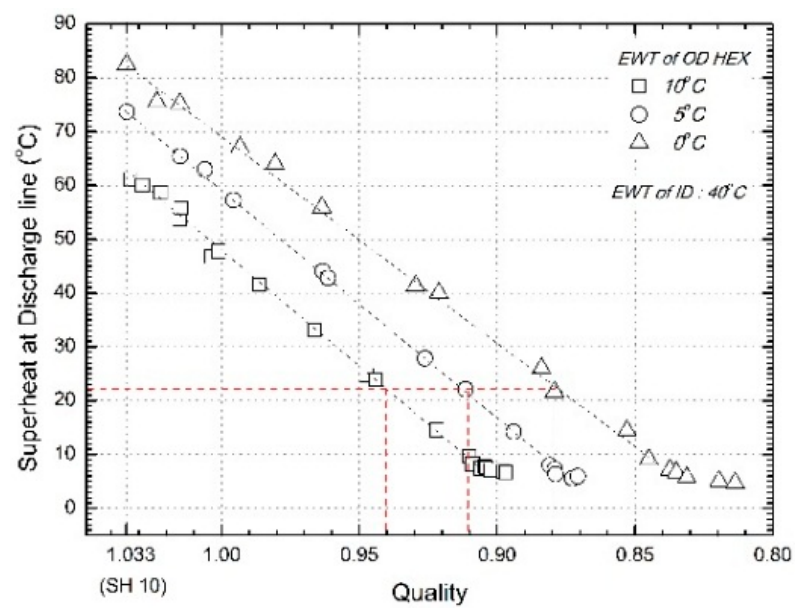

Figure 16. Superheat at the discharge line as a function of quality for different EWT of OD HEX.

\section{Conclusions}

In this study, in order to investigate the influence of wet compression on the performance of a heat pump system with a $3.5 \mathrm{Kw}$ capacity, we performed an experiment under the ISO 13256-2 test conditions, varying the quality at the compressor inlet by controlling EEV, using R32 as the working fluid. The results demonstrate that the discharge temperature decreased and the refrigerant mass flow rate increased, due to the rising liquid droplets with respect to a decrease in the quality. The heating capacity increased with an increasing EWT of OD HEX and decreasing quality, due to the increasing refrigerant mass flow rate, while it decreased rapidly at a quality of $0.91,0.88$, and 0.84 , for EWT of OD HEX at $10^{\circ} \mathrm{C}, 5^{\circ} \mathrm{C}$, and $0{ }^{\circ} \mathrm{C}$, respectively, due to the loss of the mass flow rate caused by a back flow of liquid refrigerant into the suction chamber. The power input remained almost unchanged during dry compression, while it increased with decreasing quality during wet compression, which was also due to an increase in the mass flow rate, and then sharply decreased due to the loss of the mass flow rate. When the EWT of $\mathrm{OD} \operatorname{HEX}$ was $10{ }^{\circ} \mathrm{C}, 5{ }^{\circ} \mathrm{C}$, and $0{ }^{\circ} \mathrm{C}$, the power input increased by a maximum of $10 \%, 12.7 \%$, and $14.4 \%$, respectively, when compared to that of SH 10 . The COP then increased from $\mathrm{SH} 10{ }^{\circ} \mathrm{C}$ until it reached a maximum value at a quality of ca. 0.94 to 0.90 in the two-phase mixture region, according to the EWT of OD HEX, and then decreased with quality. This indicates that the heating capacity consistently increases more than the power input with decreasing quality, until an abrupt decrease; following this, the power input in the region of wet compression is proportionally larger than the increase in the heating capacity, according to the decreasing quality. The maximum COP thus occurs at specific qualities, i.e., as mentioned above, ca. 0.94 to 0.90 . When the EWT of OD HEX was $10^{\circ} \mathrm{C}, 5{ }^{\circ} \mathrm{C}$, and $0{ }^{\circ} \mathrm{C}$, the COP increased by a maximum of ca. $12.4 \%, 10.6 \%, 10.2 \%$, respectively, when compared to that of $\mathrm{SH} 10^{\circ} \mathrm{C}$.

In summary, wet compression by controlling the EEV opening could provide an alternative solution for systems operating at a high compression ratio, as long as care is taken with regards to excessive liquid droplets, which may raise the load of the compressor. In addition, the superheat at the discharge line could be proposed as a proper controlling parameter for adjusting the quality at the suction line by varying the opening of the expansion valve during wet compression.

Author Contributions: K.S., D.L. conceived and designed the experiments; K.S. did necessary calibrations for the measuring devices and D.L. performed the experiments; K.S. and D.L. analyzed the data; J.L. contributed reagents/materials/analysis tools and wrote the paper.

Conflicts of Interest: The authors declare no conflict of interest. 


\section{Abbreviations}

$\begin{array}{ll}\text { COP } & \text { coefficient of performance }(-) \\ \text { EEV } & \text { electronic expansion valve }(-) \\ \text { EWT } & \text { entering water temperature }\left({ }^{\circ} \mathrm{C}\right) \\ \text { ID HEX } & \text { indoor heat exchanger }(-) \\ \text { OD HEX } & \text { outdoor heat exchanger }(-) \\ \text { SH } & \text { superheat at compressor inlet }\left({ }^{\circ} \mathrm{C}\right) \\ c_{\mathrm{p}} & \text { specific heat of water }\left(\mathrm{kJ} \cdot \mathrm{kg}^{-1} \cdot \mathrm{K}^{-1}\right) \\ \text { EWT } & \text { entering water temperature at evaporator }\left({ }^{\circ} \mathrm{C}\right) \\ h_{\text {in,evap. }} & \text { enthalpy at evaporator inlet }\left(\mathrm{kJ} \cdot \mathrm{kg}^{-1}\right) \\ h_{\mathrm{g}, \text { sat. }} & \text { saturated vapor enthalpy }\left(\mathrm{kJ} \cdot \mathrm{kg}^{-1}\right) \\ h_{1, \text { sat. }} & \text { saturated liquid enthalpy }\left(\mathrm{kJ} \cdot \mathrm{kg}^{-1}\right) \\ h_{\mathrm{o}, \text { evap. }} & \text { enthalpy at evaporator outlet }(\mathrm{kJ} \cdot \mathrm{kg}-1) \\ L W T_{\text {evap. }} & \text { leaving water temperature of evaporator }\left({ }^{\circ} \mathrm{C}\right) \\ \dot{m}_{\mathrm{r}} & \text { mass flow rate of refrigerant }\left(\mathrm{kg} \cdot \mathrm{s}^{-1}\right) \\ \dot{m}_{\mathrm{w}} & \text { mass flow rate of water }\left(\mathrm{kg} \cdot \mathrm{s}^{-1}\right) \\ \dot{Q}_{\mathrm{w}, \text { evap. }} & \text { water capacity at evaporator }(\mathrm{W}) \\ \dot{Q}_{\mathrm{r}, \text { evap. }} & \text { refrigerant capacity at evaporator }(\mathrm{W})\end{array}$

\section{References}

1. Ferreira, C.A.I.; Zaytsev, D.; Zamfirescu, C. Wet compression of pure refrigerants. In Proceedings of the International Compressor Engineering Conference, West Lafayette, IN, USA, 17-20 July 2006; Paper 1778.

2. Itard, L.C.M. Wet compression versus dry compression in heat pumps working with pure refrigerants or non-azeotropic mixtures. Int. J. Refrig. 1995, 18, 495-504. [CrossRef]

3. Vorster, P.P.J.; Meyer, J.P. Wet compression versus dry compression in heat pumps working with pure refrigerant or non-azeotropic binary mixtures for different heating application. Int. J. Refrig. 2000, 23, 292-311. [CrossRef]

4. Liu, Z.; Soedel, W. A mathematical model for simulatingliquid and vapor two-phasecompression processes and investigating slugging problems in compressors. HVAC \& R Res. 1995, 1, 99-109.

5. Afejei, T.; Suter, P.; Favrat, D. Experimental analysis of an inverter-driven scroll compression with liquid injection. In Proceedings of the International Compressor Engineering Conference, West Lafayette, IN, USA, 14-17 July 1992. Paper 845.

6. Dutta, A.K.; Yanagisawa, T.; Fukutta, M. A study on compression characteristic of wet vapor refrigerant. In Proceedings of the International Compressor Engineering Conference, West Lafayette, IN, USA, 23-26 July 1996; Paper 1112.

7. Sami, S.M.; Aucoin, S. Behaviour of refrigerant mixtures with gas/liquid injection. Int. J. Energy Res. 2003, 27, 1265-1277. [CrossRef]

8. Wang, S.; Gu, G.; Dickson, T. Investigation of the effects of vapour quality and oil concentration on performance of a swash plate compressor. Int. J. Energy Res. 2006, 30, 835-849. [CrossRef]

9. Cho, H.; Chung, J.T.; Kim, Y. Influence of liquid refrigerant injection on the performance of an inverter-driven scroll compressor. Int. J. Refrig. 2003, 26, 87-94. [CrossRef]

10. Feng, C.; Jiyou, F.; Ziwen, X.; Liansheng, L. Study on performance of a heat pump water heater using suction stream liquid injection. Appl. Therm. Eng. 2009, 29, 2942-2948. [CrossRef]

11. Roh, C.W.; Yoo, J.W.; Kim, M.S. Vapor refrigerant injection techniques for heat pump system: The latest literature review and discussion. Int. J. Air-Cond. Refrig. 2014, 22, 143002. [CrossRef]

12. Aikins, K.A.; Lee, S.H.; Choi, J.M. Technology review of two-stage vapor compression heat pump system. Int. J. Air-Cond. Refrig. 2013, 21, 1330002. [CrossRef]

13. Hou, Y.; Ma, J.; Li, C.; Cao, J.; Liu, X. Experimental investigation on the influence of EEV opening on the performance of transcritical $\mathrm{CO}_{2}$ refrigeration system. Appl. Therm. Eng. 2014, 65, 51-56. [CrossRef]

14. Water Source Heat Pumps-Testing and Rating for Performance-Part 2: Water to Water and Brine to Water Heat Pumps; ISO 13256-2:1998; ISO: Geneva, Switzerland, 1998.

15. ASHRAE Guideline 2, Engineering Analysis of Experimental Data; ASHRAE: Atlanta, GA, USA, 2005. 
16. Xu, X.; Hwang, Y.; Radermacher, R. Refrigerant injection for heat pumping/air conditioning system: Literature review and challenges discussions. Int. J. Refrig. 2011, 34, 402-415. [CrossRef]

17. Stoecker, W.F. Refrigeration and Air-Conditioning; McGraw-Hill: New York, NY, USA, 1983.

18. Lee, D.; Seong, K.J.; Lee, J. Performance investigation of vapor and liquid injection on a refrigeration system operating high compression ratio. Int. J. Refrig. 2015, 53, 115-125. [CrossRef]

19. Dutta, A.K.; Yanagisawa, T.; Fukuta, M. An investigation of the performance a scroll compressor under liquid refrigerant injection. Int. J. Refrig. 2001, 24, 577-587. [CrossRef]

20. Wang, X.; Hwang, Y.; Radermacher, R. Two-stage heat pump system with vapor injected scroll compressor using R410A as a refrigerant. Int. J. Refrig. 2009, 32, 1442-1451. [CrossRef]

21. Laughman, R.C.; Armstrong, P.R.; Norford, L.K.; Leeb, S.B. The detection of Liquid slugging phenomena in reciprocating compressor via power measurements. In Proceedings of the International Compressor Engineering Conference, West Lafayette, IN, USA, 17-20 July 2006; Paper 1816.

22. Swanpoel, W. Wet Compression Versus dry Compression in Refrigeration Cycles Working with Pure or Non-Azeotropic Refrigerant Mixtures for Air Conditioners. Master's Thesis, Rand Afikaans University, Johannesburg, South Africa, 2008.

23. Mithraratne, P.; Wijeysundera, N.E. An experimental and numerical study of hunting in thermostaticexpansion-valve-controlled evaporators. Int. J. Refrig. 2002, 25, 992-998. [CrossRef]

(C) 2017 by the authors. Licensee MDPI, Basel, Switzerland. This article is an open access article distributed under the terms and conditions of the Creative Commons Attribution (CC BY) license (http:/ / creativecommons.org/licenses/by/4.0/). 